\title{
LA CUESTIÓN PREJUDICIAL DE CONSTITUCIONALIDAD EN FRANCIA ¿SOLUCIÓN O PROBLEMA?
}

\author{
PIERRE BON \\ Profesor de Derecho Público \\ Universidad de Pau et des Pays de l'Adour
}
SUMARIO
I. Introducción.
II. Una solución parcialmente original en el ámbito del derecho comparado.
III. ¿Un problema de competitividad respec- to al control de convencionalidad?

\section{INTRODUCCIÓN ${ }^{1}$}

El control de constitucionalidad de las leyes en Francia ha sido tradicional y principalmente un control abstracto y previo ${ }^{2}$; no en vano nuestra Constitución únicamente estableció como preceptivo el control de constitucionalidad de las leyes orgánicas, antes de su promulgación, y de los reglamentos de las asambleas parlamentarias, antes de su aplicación; aquéllas y éstos, como es bien sabido, deben someterse al Consejo Constitucional. Se estableció como facultativo, el control del resto de leyes por parte del Consejo Constitucional. Para este supuesto la Constitución determinó, como es sabido, un número limitado de sujetos legitimados en orden a remitir, con idéntica finalidad, las leyes ante aquél: el Presidente de la República, el Primer Ministro, el Presidente de la Asamblea Nacional, el Presidente del Senado y sesenta diputados o sesenta senadores $^{3}$. El pronunciamiento del Consejo Constitucional debía producirse en el

1 Traducción de M. J. de las Heras y F. Reviriego.

2 La hipótesis tradicional del control a posteriori (artículo 37, parágrafo segundo de la Constitución; aplicación de la doctrina del Consejo Constitucional de 25 de enero de 1985 "Estado de emergencia en Nueva Caledonia") sólo tiene en efecto una aplicación limitada. 904).

3 No fue hasta 1974 cuando se amplió la legitimación a las minorías parlamentarias (L.C. 74- 
plazo de un mes, aunque a petición del Gobierno y si existiera urgencia podía reducirse incluso a ocho días. Esto provocaba evidentemente, ante la ausencia de un procedimiento de cuestión de inconstitucionalidad, una suerte de laguna por la existencia de leyes que hubieran escapado de tal control y sobre las que, estando en vigor, existieran dudas de constitucionalidad; ello porque los sujetos referidos supra, únicos legitimados a tal efecto, y que, lógicamente, se guían en su actuación esencialmente por criterios políticos y no estrictamente jurídicos, no hubieran considerado oportuno en su momento haberlas elevado al Consejo para tal control.

En el supuesto de leyes preconstitucionales, su eventual inconstitucionalidad puede ser solventada por la actuación del juez ordinario, en la medida en que se considere, en el caso de una contradicción directa, que nos encontramos ante un mero problema de aplicación de la ley en el tiempo que depende de la competencia natural del juez ordinario, y no solamente de un problema de jerarquía Constitución-Ley que, en un sistema de justicia constitucional concentrada, depende de la competencia exclusiva del juez constitucional ${ }^{4}$. Y, de hecho, al menos el Consejo de Estado ha optado por esta vía ya que, por ejemplo, ha aceptado controlar si la Ley del 3 de abril de 1955 que estableció un estado de emergencia había sido o no derogada por la entrada en vigor de la Constitución de $1958^{5}$ o si sucedía lo propio con una ordenanza de 2 de noviembre de 1945 relativa al estatuto de los «huissiers de justice ${ }^{6}$ " con relación al párrafo sexto del preámbulo de la Constitución de 1946, a su vez reproducido por el de la vigente Constitución ${ }^{7}$.

En el caso de leyes aprobadas con posterioridad a la entrada en vigor de la Constitución que no hubieran sido remitidas para tal control al Consejo Constitucional por los sujetos referidos, el problema resulta más complejo y generaba una de las lagunas más importantes de nuestro Estado de derecho con la denominada teoría de la "ley pantalla". Así, por ejemplo, el juez administrativo al conocer de un acto administrativo aprobado en aplicación de una ley contraria a la Constitución, no podía controlar la constitucionalidad de la ley ni elevar al Consejo sus dudas de constitucionalidad. El juez, en consecuencia, se veía obligado a concluir la legalidad del acto administrativo a pe-

4 En Italia y España el juez ordinario no es el único competente para su conocimiento (derogación), sino igualmente el juez constitucional (jerarquía); véase, por ejemplo, las sentencias de la Corte Constitucional Italiana de 14 de junio de 1956 (1/1956) o del Tribunal Constitucional español (STC 4/1981, de 2 de febrero), Les grandes décisions des cours constitutionnelles européennes (P. Bon - D. Maus, Dirs.), Dalloz, 2008, respectivemente, págs. 89 y 92.

5 Consejo de Estado, 21 de noviembre de 2005, juge des référés, Boisvert, Rec. Cons. d'Et., pág. 517; AJDA 2006, pág. 357, Cron. C. Landais y F. Lenica; BJCL 11/05, pág. 754.

6 Nota del traductor: Si bien resulta habitual la traducción de huissiers de justice por nuestro agente judicial no se corresponde exactamente ni en competencias ni en naturaleza.

7 Consejo de Estado, 16 de diciembre de 2005, assemblée, Ministre des affaires sociales, $d u$ travail et de la solidarité et Syndicat national des huissiers de justice, Rec. Cons. d'Et., pág. 570; RFDA 2006, pág. 41, Concl. J.-F. Stahl; RJEP/CJEG, n 629, mars 2006, pág. 128, Concl. J.-F. Stahl; AJDA 2006, pág. 357, Cron. C. Landais y F. Lenica. 
sar de su inconstitucionalidad. En otras palabras, la supremacía de la Constitución sobre la ley queda cuestionada en ausencia de una vía jurídica adecuada que permitiese poner en tela de juicio la ley.

Esta situación resultaba todavía más paradójica porque los tribunales administrativos $^{8}$ (como en otro momento habían hecho los tribunales ordinarios al seguir esta vía antes que el Consejo de Estado tras un categórico fallo de la Corte de Casación') podían asegurar la supremacía de los tratados internacionales sobre las leyes dentro del marco de control de "convencionalidad" de las leyes. Dicho de otro modo, eran competentes para inaplicar una ley contraria a un tratado internacional (de tal forma que la ley no "hiciera pantalla" entre dicho tratado y un acto administrativo) pero no lo eran en el caso de que "sólo" se considerara inconstitucional, ni tampoco para solicitar al Consejo Constitucional, mediante una cuestión prejudicial, un pronunciamiento sobre la constitucionalidad de la ley en cuestión. Todo lo anterior se traducía en la práctica en una incontestable devaluación de la Constitución, que presentaba para el ciudadano menor relevancia que, por ejemplo, el Convenio Europeo de Derechos Humanos en la defensa de los derechos fundamentales frente a la ley. Por más que, de hecho, los dos textos proclamaran grosso modo los mismos derechos, no era posible que el juez garantizase la supremacía de la Constitución sobre la ley, pero sí una decisión tendente a garantizar la primacía del Convenio. Dicho en otros términos, le resultaba de mayor utilidad al ciudadano el conocimiento de la jurisprudencia del Tribunal Europeo de Derechos Humanos que la del propio Consejo Constitucional.

La reforma constitucional de julio de 2008 corrige afortunadamente esta inquietante deriva de nuestro sistema constitucional. Esto es, la prevalencia en la práctica de valores o reglas externas sobre los derivados del propio pacto del que dimanó nuestra ley fundamental. La reforma del artículo 61.1 del texto constitucional ${ }^{10}$ permite, en efecto, suscitar una suerte de cuestión de inconstitucionalidad por vía de excepción.

La conciencia de este déficit en nuestro sistema constitucional viene de atrás y no ha sido la primera ocasión en que se ha tratado de solventar; no en vano cabe recordar los dos intentos frustrados de reforma constitucional de $1990^{11}$ (bajo la rúbrica de "excepción de inconstitucionalidad") y $1993^{12}$. Ambos proyectos (que seguían las recomendaciones de los Informes Ve-

8 Consejo de Estado, "Arrêt Nicolo", 20 de octubre 1989.

9 Corte de Casación, "Arrêt Société des cafés Jacques Vabre", 24 de mayo de 1975.

10 Véase, A. Roux, "Le nouveau Conseil constitutionnel: vers la fin de l'exception française?", JCPG 2008.I.175; P. CASSIA, "Le renvoi préjudiciel en appréciation de constitutionnalité, une "question" d'actualité", RFDA 2008, pág. 877.

11 Proyecto de Ley Constitucional n ${ }^{\circ} 1.203$ de reforma de los artículos 61, 62 y 63 de la Constitución que instaura un control de constitucionalidad de las leyes por vía de excepción (registrado en la Asamblea Nacional el 30 de marzo de 1990).

12 Proyecto de Ley Constitucional $n^{\circ} 231$ de reforma de los títulos VII, VIII, IX y X de la Constitución (registrado en el Senado el 11 de marzo de 1993). 
de $^{13}$ y Balladur ${ }^{14}$, aunque este último todavía iba más allá de lo ahora articulado) no pudieron ser aprobados en última instancia por la oposición del Senado.

Tras la reforma de 2008, el artículo 61 dispone en efecto que "cuando, con ocasión de un procedimiento judicial en curso, se considere que una disposición legislativa vulnera los derechos y libertades garantizados por la Constitución, la cuestión podrá ser planteada ante el Consejo Constitucional por el Consejo de Estado o por la Corte de Casación. De esta forma se ha dotado a la institución de un control concreto (en el sentido que este término tiene en la teoría general de la justicia constitucional), del que desafortunadamenta carecía hasta la fecha el sistema jurisdiccional francés.

Control que, no obstante, presenta particularidades si lo comparamos con lo previsto en líneas generales por la legislación de la mayor parte de los países europeos, encontrándonos así ante una solución parcialmente original en este ámbito.

Solución que, por otra parte, no sabemos si llega demasiado tarde una vez consolidado ese control a posteriori de las leyes dentro del marco del control de convencionalidad. ¿Resultará operativo o se corre el riesgo de que se plantee un problema de competitividad en relación con éste?

\section{UNA SOLUCIÓN PARCIALMENTE ORIGINAL EN EL ÁMBITO DEL DERECHO COMPARADO}

El sistema articulado en nuestro país con relación a la cuestión prejudicial de constitucionalidad presenta dos singularidades frente a otras experiencias comparadas. Por un lado, que la cuestión sólo puede ser planteada cuando entren en juego derechos fundamentales; por otro, sólo puede ser planteada por los jueces ordinarios supremos. Ahora veremos en qué medida..

Con relación al primero de esos dos puntos, hay que señalar que mientras en la práctica totalidad de los países la cuestión de inconstitucionalidad puede ser planteada independientemente del motivo de inconstitucionalidad, no sucede lo mismo en Francia; aquí tan solo puede ser planteada en el supuesto de que se demuestre que una disposición legislativa vulnera los derechos y libertades garantizados por la Constitución ${ }^{15}$. Esto supone que puede

13 Journal Officiel, 16 de febrero de 1993, págs. 2548-2549. $87-91$.

14 Une cinquième République plus démocratique, www.comite-constitutionnel.fr, págs.

15 Sobre la nueva redacción del artículo 61.1 de la Constitución es reseñable que según el proyecto de revisión constitucional de 1990 la interposición sólo era posible respecto de los derechos fundamentales reconocidos a toda persona por la Constitución; fórmula recogida por el Informe Vedel, por el proyecto de reforma constitucional de 1993 y, de forma similar por el Informe Balladur ("derechos y libertades fundamentales reconocidos por la Constitución". La fórmula de 2008 es sin duda más satisfactoria en la medida en que no sólamente evoca las liber- 
haber un control a posteriori de la ley y que la denominada teoría de la "ley pantalla" no rige cuando están en juego los derechos y las libertades constitucionales; a sensu contrario, no cabe control a posteriori, siendo de aplicación dicha teoría cuando no sea así.

Desde el punto de vista de la justicia constitucional cabe plantearse donde ubicar la cuestión prejudicial francesa. ¿Estamos ante la competencia en materia de control concreto de las leyes, tal y como lo encontramos en Alemania, Austria, Bélgica, España o Italia y donde sólo el juez ordinario puede plantear la cuestión de constitucionalidad con ocasión de la duda surgida en un proceso ordinario que se sigue ante él? O, por el contrario, ¿se enmarca en la vía específica abierta a los individuos cuando se lesionan sus derechos fundamentales y no han logrado remedio ante la justicia ordinaria? - vía esta que encontramos en España con el recurso de amparo-. En otros términos, ¿se trata de que las partes planteen al juez ordinario que existe un problema de constitucionalidad y que es necesario elevar la cuestión a la jurisdicción constitucional? ¿O se trata, por el contrario, de permitir a las partes acceder a ésta cuando el juez ordinario no haya considerado la existencia de un problema en materia de constitucionalidad?

Como ya hemos indicado, es evidente que nos encontramos ante el primer supuesto. Ciertamente, tanto ahora como en los dos intentos de reforma precedentes (1990 y 1993), se argumentó que la nueva vía que se articulaba abría la jurisdicción constitucional a los ciudadanos; mas, sin duda, resulta una afirmación exagerada. No cabe negar que la reforma ofrece a los ciudadanos derechos suplementarios, mas tampoco que es el juez ordinario, de forma autónoma quien decide remitir al Consejo Constitucional la cuestión; de tal manera que, en realidad, la reforma abre al juez ordinario la vía del juez constitucional. Tenemos pues un tema de competencia que depende, por su propia técnica, del control concreto de las leyes. Se trata de un control concreto parcial en tanto que sólo se ejerce un control de la ley en lo que se refiere a las disposiciones relativas a los derechos y libertades. Pero es, aún así, un control concreto, puesto que la legitimación sólo corresponde al juez ordinario.

Queda por aclarar de qué juez ordinario se trata y, en este punto, dónde encontramos con la otra singularidad que reviste la cuestión de constitucionalidad francesa, que a renglón seguido abordaremos: esto es, que sólo pueda ser planteada por los jueces ordinarios supremos.

Mientras que, en la mayor parte de los países en los que existe un control concentrado y concreto, la cuestión de constitucionalidad puede ser planteada al juez constitucional por cualquier juez ordinario, independientemente de

tades y los derechos (lo que hacía también el Informe Balladur) sino que suprime también el calificativo fundamentales evitando de esta manera que se plantee la cuestión de abordar si en el seno de las libertades y derechos reconocidos por la Constitución hubiera algunos que fueran fundamentales y otros que no lo fueran (cuestión baladí en nuestro país porque nosotros definimos las libertades y derechos fundamentales como todos los que son reconocidos por un texto de valor supra legislativo), L. Favoreu y otros, Droit des libertés fondamentales, Dalloz, 2005, 3. ${ }^{a}$ ed., pág. 2. 
su rango jerarquico, el sistema francés, tras la reforma de 2008, no abre esta posibilidad más que a dos órganos: el Consejo de Estado y la Corte de Casación. En otras palabras, planteada una cuestión de constitucionalidad ante un juez ordinario, si ésta resulta pertinente, deberá proceder a paralizar la instrucción, remitiendo la cuestión al juez supremo del orden jurisdiccional al que pertenezca y sólo en el supuesto de que éste considere que efectivamente dicho problema de constitucionalidad existe, se podrá remitir el asunto al Consejo Constitucional. Algo parecido contemplaban el proyecto de reforma constitucional presentado en $1990^{16}$, el Informe Vede ${ }^{17}$, o el posterior proyecto de reforma de $1993^{18}$. El Informe Balladur, en cambio, como antes apuntábamos, se inclinaba por una fórmula un tanto diversa más en armonía con las previsiones habituales en el ámbito comparado, en tanto que preveía que el Consejo Constitucional pudiera ser requerido a solicitud del Consejo de Estado y la Corte de Casación, pero también de jurisdicciones subordinadas a aquellas o de cualquier otra jurisdicción no perteneciente ni al primero ni a la segunda, esto es, cualquier juez ordinario.

Son varias las razones que pueden argumentarse para haber optado por la fórmula más restrictiva.

Por un lado, desde un punto de vista técnico se trata de evitar la sobrecarga del Consejo Constitucional, y a ello debe ayudar el papel de filtro que ejercerán el Consejo de Estado y la Corte de Casación. Esta nos parece una razón de peso. El Consejo Constitucional tiene a su cargo la resolución de un número elevado recursos dentro del marco del control abstracto a priori de la constitucionalidad de leyes que, en aplicación del artículo 61 de la Constitución, ejerce a instancia de las autoridades políticas y fuera de todo litigio concreto.

Como muestra de esa hipotética sobrecarga cabe recordar la desafortunada experiencia del control previo de constitucionalidad en España entre 1980 y $1985^{19}$, un tipo de control que sólo es admisible políticamente si se ejecuta en plazos de tiempo muy breves suspendiéndose así mínimamente la entrada en vigor de la ley; recordemos que es de un mes en Francia (ocho días en supuestos de urgencia) y veinticinco días en Portugal. Este control $a$ priori, si termina por remitir ad calendas graecas la entrada en vigor de la ley, está condenado políticamente ${ }^{20}$. Una vez dicho esto, lo cierto es que la

16 «Sobre el reenvio del Consejo de Estado, Corte de Casación o de cualquier otra jurisdicción francesa que no provenga ni del uno ni del otro".

17 Idéntica fórmula salvo que el adjetivo "francesa" desaparece.

18 Idéntica fórmula que la planteada por el Informe Vedel.

19 Este «recurso previo de inconstitucionalidad contra proyectos de Estatutos de Autonomía y de leyes orgánicas", no previsto constitucionalmente, se introdujo en sede legal (Ley Orgánica 2/1979, de 3 de octubre, reguladora del Tribunal Constitucional).

20 Podemos leer, en el preámbulo de la L.O. 4/1985, de 7 de junio, por la que se derogó este recurso, que la "experiencia acumulada ha venido a mostrar que este recurso previo se ha configurado como un factor distorsionador de la pureza del sistema de relación de los poderes constitucionales del estado, con consecuencias inesperadas y metaconstitucionales en la ultima 
experiencia española es significativa sólo parcialmente. La sobrecarga del Tribunal Constitucional español viene determinada por los recursos de ampa$\mathrm{rO}^{21}$; hecho que ha llevado a un sector de la doctrina a insistir que el Tribunal Constitucional es, en la práctica, un Tribunal de amparo. La reciente reforma de 2007 operada en virtud de la Ley Orgánica 6/2007, de 24 de mayo ${ }^{22}$, ha pretendido solventar este problema aunque todavía es pronto para ver sus efectos $^{23}$. Por ello, a la vista de esta experiencia, no cabe concluir que una hipotética ampliación de la legitimación a cualquier tribunal en Francia hubiera provocado per se el colapso del Consejo Constitucional, ni una sobrecarga que le impidiera ejercer de manera satisfactoria su misión de control abstracto a priori de las leyes, sobre todo si, paralelamente se estableciera que los miembros del Consejo, como en el resto de países, desempeñen su función a tiempo completo.

Desde un punto de vista sociopolítico no es desdeñable pensar que la atribución exclusiva a estos órganos pretende también mantener la situación de poder de los mismos, pues la decisión de haber atribuido a cualquier juez ordinario esta competencia quizá hubiera chocado con la posición de privilegio de aquellos en nuestro sistema jurisdiccional, especialmente aquí, donde se plantea una suerte de diálogo directo con la jurisdicción constitucional.

Atribuir en exclusiva la legitimación únicamente al Consejo de Estado y a la Corte de Casación puede entrañar un riesgo: el que uno y otro se erijan en una suerte de tribunal constitucional bis. Cuando un juez ordinario decide someter una cuestión al juez constitucional realiza, quiera o no, un juicio de

fase de procedimiento de formación de la ley" y asimismo que conforme "la redacción y la eficacia del artículo 79 de la L.O. 2/1979 pueden tener difícil encaje en las previsiones del artículo 91 de la constitución, que señala un plazo determinado de sanción real de las leyes aprobadas por las cortes, sin prever plazos de espera de los eventuales proyectos que, por haber sido aprobados por las cámaras, han dejado de serlo para transformarse en leyes, si bien carentes todavía de sanción".

21 A título de ejemplo, en 2008, de 10.410 asuntos ingresados, 10.279 (el 98,74\% del total) correspondieron a recursos de amparo mientras que sólamente $93(0,89 \%)$ a cuestiones de constitucionalidad, Memoria del Tribunal Constitucional de 2008 accesible en su página web.

$22 \mathrm{El}$ artículo 49.1 de la L.O.T.C. queda redactado de la siguiente manera: "1. El recurso de amparo constitucional se iniciará mediante demanda en la que se expondrán con claridad y concisión los hechos que la fundamenten, se citarán los preceptos constitucionales que se estimen infringidos y se fijará con precisión el amparo que se solicita para preservar o restablecer el derecho o libertad que se considere vulnerado. En todo caso, la demanda justificará la especial trascendencia constitucional del recurson.

23 Como se apuntó en la exposición de motivos de la citada Ley "frente al sistema anterior de causas de inadmisión tasadas, la reforma introduce un sistema en el que el recurrente debe alegar y acreditar que el contenido del recurso justifica una decisión sobre el fondo por parte del Tribunal en razón de su especial trascendencia constitucional, dada su importancia para la interpretación, aplicación o general eficacia de la Constitución. Por tanto, se invierte el juicio de admisibilidad, ya que se pasa de comprobar la inexistencia de causas de inadmisión a la verificación de la existencia de una relevancia constitucional en el recurso de amparo formulado. Esta modificación sin duda agilizará el procedimiento al transformar el examen de admisión actual en la comprobación en las alegaciones del recurrente de la existencia de relevancia constitucional en el recurso". 
constitucionalidad; juicio que es definitivo en el proceso en que se plantea la cuestión. Por tanto, el peso de este juicio de constitucionalidad y la competencia que pueda causar al poder de interpelación del juez constitucional será mayor cuando menos numerosos y de mayor rango jerárquico sean los tribunales susceptibles de plantearlo. Desde esta perspectiva cabe distinguir tres posibilidades.

La primera, mayoritaria en nuestro entorno más cercano, aquella en la que todos los jueces y tribunales pueden plantear dicha cuestión, esto es, emitir el juicio de constitucionalidad al que se ha hecho alusión anteriormente. Esta es la hipótesis en la que los riesgos de concurrencia del juez constitucional son menores.

En segundo lugar, aquella en la que únicamente algunos tribunales pueden llegar a la corte constitucional. Los riesgos de concurrencia son ya más elevados. En Alemania, por ejemplo, la versión inicial de la Ley reguladora del Tribunal Constitucional Federal no otorgaba en principio legitimación más que a los tribunales federales superiores ${ }^{24}$ hecho que, como ha apuntado la doctrina $^{25}$, llevó a que la Sala Primera (Civil) del Tribunal de Justicia Federal aprovechara para atribuirse un rol de cámara constitucional. Ello provocó la reforma del sistema en 1956 ampliándose la legitimación a todos los tribunales. Por su parte, en Austria, el Tribunal Constitucional Federal sólo puede ser instado por la Corte administrativa, la Corte Suprema de Justicia o todo tribunal llamado a decidir en segunda instancia, pero no por un juez de primera instancia; esto representa una treintena de autoridades, hecho que ha permitido a algunos autores afirmar que existirían ese mismo número de jueces constitucionales ${ }^{26}$.

Finalmente nos encontramos el supuesto en el que únicamente la instancia suprema de la justicia ordinaria (en un sistema de unidad de jurisdicción), o las dos instancias supremas, administrativa y judicial (en un sistema de dualidad de jusrisdicciones), pueden plantear la cuestión de constitucionalidad. Esta última es la solución adoptada por Francia tras la reforma constitucional de 2008. Y es la opción bajo la que, sin duda, resulta más probable que se favorezca una mayor competencia entre las tres altas instancias. Ciertamente, se obliga al "diálogo de jueces» y al esfuerzo de evitar que entre ellas se produzcan divergencias de jurisprudencia demasiado llamativas. Esto no quiere decir, sin embargo, que el Consejo de Estado y la Corte de Casación estén dispuestos a interpretar los derechos y las libertades constitucionales siguiendo al pie de la letra la jurisprudencia del Consejo Constitucional. Con relación a la ley cuya constitucionalidad sea cuestionada ante el juez ordinario,

24 Tribunal de Justicia Federal para las leyes federales y tribunales de rango más elevado de los Länder, en el caso de una Ley del Land.

25 J. C. BÉguin, Le contrôle de la constitutionnalité des lois en République fédérale d'Allemagne, Economica, 1982, pág. 98.

26 Véase sobre esta cuestión el analisis crítico de S. Peyrou-Pistouley, La Cour constitutionnelle et le contrôle de la constitutionnalité des lois en Autriche, Economica, págs. 282-283. 
al no haber sido conocida previamente por el juez constitucional, hay que apuntar que sus decisiones no tendrán autoridad de "cosa juzgada", sino de "Cosa interpretada". Si la primera tiene fuerza vinculante, la segunda tan sólo tiene fuerza moral o persuasiva ${ }^{27}$, de tal modo que si en un momento dado, el Consejo de Estado o la Corte de Casación se encuentran tentados a interpretar de forma autónoma la Constitución, prevalecerá si el juez no decide elevarla al Consejo Constitucional. Viniendo de instituciones tan consolidadas y prestigiosas, este tipo de interpretación autónoma estaría dotada evidentemente de mayor relevancia que si proviniera de cualquier juez de primera instancia y podría hacerles aparecer como jueces constitucionales bis como antes apuntamos. Sería por tanto necesario esperar que el "diálogo de jueces", al que se ha hecho referencia anteriormente y al que ya están habituados (los jueces), permita evitar este riesgo hasta donde sea posible.

En consecuencia, la limitación de la cuestión prejudicial a la violación de los derechos fundamentales y la restricción de la legitimación al Consejo de Estado y a la Corte de Casación, son las dos peculiaridades que presenta la cuestión prejudicial "a la francesa", en comparación con el control concreto tal y como se regula en la práctica totalidad de los países. Particularidades que pueden ser analizadas desde una perspectiva negativa por su carácter limitado, pero que sin duda representan un progreso incontestable en nuestro Estado de Derecho. Queda por saber si la reforma no llega tarde o si permitirá detener ese proceso de devaluación de la Constitución al que hacíamos alusión apareciendo el nuevo procedimiento ante los ciudadanos y los jueces ordinarios al menos tan interesante como el propio control de convencionalidad. Este es el problema que conviene abordar en este momento.

\section{III. ¿UN PROBLEMA DE COMPETITIVIDAD RESPECTO AL CONTROL DE CONVENCIONALIDAD?}

Desde tiempo atrás la jurisdicción ordinaria, con el Consejo de Estado y la Corte de Casación a la cabeza, se encuentran habituados al control de convencionalidad de las leyes y de los actos infralegislativos, control cuya potencialidad ha podido ser ya valorada en este tiempo por los propios jueces. ¿Cabe esperar, tras la reforma de 2008, que se produzca una apuesta decisiva respecto del control de constitucionalidad multiplicando las cuestiones prejudiciales? En otros términos ¿va a resultar tan atractivo el control de constitucionalidad como el control de convencionalidad? Sin duda es demasiado pronto para dar una respuesta categórica a esta afirmación, pero al menos podemos apuntar tres consideraciones de interés: las causas invocables, el co-

27 En palabras de R. de Gouttes, Premier avocat général ante la Corte de Casación en sus conclusiones en el fallo de la Corte de 10 de octubre de 2001, Breisacher, RFDC 2002, pág. 68. 
nocimiento de la jurisprudencia constitucional y el plazo para obtener una respuesta definitiva del juez.

\section{Causas invocables}

A primera vista, existe un punto sobre el que el control de constitucionalidad parece ofrecer menos potencialidades que el control de convencionalidad: las causas invocables. En el marco del control de la constitucionalidad hemos visto que, justificada o injustificadamente, el constituyente de 2008 ha entendido que debía acotar la cuestión prejudicial de constitucionalidad a los supuestos de vulneración, por una disposición legislativa, de los derechos y libertades garantizados constitucionalmente.

En cambio, en el control de convencionalidad no existe restricción alguna; una disposición legislativa podrá ser inaplicada desde el momento que contradiga un tratado internacional sea cual fuere su contenido. Por tanto, el control de convencionalidad podría parecer más interesante que el control de constitucionalidad.

Conviene en cualquier caso matizar este punto de vista en la medida en que el tratado internacional sólo podrá ser invocado si, además de haber sido concluido regularmente y siendo aplicado por la otra parte, resulte de aplicabilidad directa. Esto puede suponer, en todo caso, un problema para buen número de tratados o cuando menos, de disposiciones, en tanto que el juez aprecia la aplicabilidad directa punto por punto, haciendo menos atractiva la vía del control de constitucionalidad.

\section{CONOCIMIENTO DE LA JURISPRUDENCIA CONSTITUCIONAL}

La articulación de este nuevo instrumento de control del que hemos venido hablando a lo largo de estas páginas provocará sin duda que los operadores jurídicos deban replantear sus estrategias.

Hasta la fecha, por todo lo referido, la jurisprudencia del Tribunal Europeo de Derechos Humanos, incluso del Tribunal de Justicia de las Comunidades Europeas, debía ser suficientemente conocida tanto por las partes como por los tribunales.

No sucedía esto, por el contrario, con relación a la jurisprudencia del Consejo Constitucional en materia de garantía de derechos y deberes constitucionales, no pudiendo afirmarse que existiera idéntico conocimiento. Sin duda es diferente en el caso de las instancias supremas que en el de los jueces ordinarios, pero no hay que olvidar que son estos últimos los que deciden elevar o no la cuestión a la última instancia de la jurisdicción a que pertenecen. Sin duda, el problema es menos agudo en el seno de la jurisdicción administrativa que en la judicial, porque la primera practica desde hace mucho tiempo el control de constitucionalidad de los actos administrativos, en cuan- 
to que el Consejo de Estado, en el ejercicio de su misión consultiva, se asegura de que los proyectos de ley, ordenanzas o decretos que le son remitidos respeten la Constitución en la totalidad de sus disposiciones ${ }^{28}$. Esto no impide que haya que realizar un esfuerzo de aggiornamento que llevará sin duda su tiempo, postergando del mismo modo la consolidación efectiva del control de constitucionalidad.

\section{Plazos PaRA OBTENER UNA RESPUESTA DEFINITIVA DEL JUEZ}

El éxito o fracaso de la cuestión prejudicial de constitucionalidad dependerá de la rapidez de su resolución. Es obvio señalar que los operadores jurídicos optarán por aquella vía que les ofrezca una respuesta más rapida; y es aquí, desde este punto de vista, donde se suscitaban algunas dudas.

Dentro del control de convencionalidad, que es un control difuso en el sentido de que puede ser ejercido por cualquier juez ordinario independientemente de su posición en la jerarquía de las cortes y tribunales, el juez ordinario que ha llegado a la conclusión de que un acto contradice un tratado, puede inaplicarlo por si mismo, incluso si de trata de un acto legislativo. Pero su decisión está subordinada, no obstante, a las propias vías de apelación y de casación, esto es, a lo que juzgará en última instancia un juez de apelación o de casación.

Dentro del marco del control de constitucionalidad, si es aplicable al caso una ley que se entiende inconstitucional, el juez ordinario no puede, evidentemente, declararla como tal, ya que el control de la constitucionalidad de las leyes es un control concentrado en las manos del juez constitucional. Lo único que podrá hacer, y ello a partir del momento en que la reforma aquí analizada entre en vigor, esto es, desde que se apruebe la ley orgánica que concretará el procedimiento, será plantear la duda de constitucionalidad, lo que supondrá la suspensión de la aplicación de la norma a la espera de la decisión del juez ordinario supremo al que pertenece o a la del Consejo Constitucional.

Por lo tanto, en un caso nos encontramos con las vías de apelación y de casación y, en el otro, con la del juez ordinario supremo y del Consejo Constitucional.

Para que la vía de la cuestión de constitucionalidad revista, cuando menos, tanta trascendencia e interés como la del control de la convencionalidad, es preciso que el tiempo que emplea el juez ordinario supremo o, en caso de fallo, el Consejo Constitucional para decidir (control de constitucionalidad),

28 En tanto que la Corte de Casación, si no ignora la Constitución en el ejercicio de su misión jurisdiccional, no la "consume" sino con moderación, prefiere siempre ir a buscar más allá (en las normas europeas e internacionales, en la noción de orden público, en los principios jurisprudenciales del derecho privado...) los elementos necesarios para la resolución del litigio. Véase, sobre esta cuestión, la destacada tesis de O. Desaulnay, L'application de la Constitution par la Cour de cassation, Dalloz, 2009. 
sea al menos del mismo orden que el empleado por el juez de apelación y el juez de casación para tomar una decisión (control de convencionalidad). En este aspecto, el nuevo artículo 61.1 de la Constitución dispone que el Consejo Constitucional puede ser requerido (cuestión de constitucionalidad) a instancias del Consejo de Estado o de la Corte de Casación que se pronuncie en el plazo determinado (por ley orgánica). Técnicamente este plazo determinado va dirigido al Consejo de Estado y la Corte de Casación, pero conviene igualmente la imposición de un plazo al Consejo Constitucional para tomar su decisión, ya que en principio el plazo de un mes que figura en el artículo 61 no concierne más que al control previo. Corresponderá a la la Ley Orgánica establecer estos plazos, resultando claro que cuánto más breves resulten éstos, más atractivo resultará el mecanismo de la cuestión de constitucionalidad; cuando más largos sean más conservará su carácter tradicional el control de covencionalidad, para desasosiego de los constitucionalistas.

$$
* \quad * \quad *
$$

TITLE: The Constitutional Interlocutory Question: Does it give us an answer or raises a problem?

ABSTRACT: In France, the judicial review of laws is mainly an a priori abstract review, which raises a crucial issue: judicial review of the laws already in effect which have not been reviewed by the French Constitutional Council. The 23 July 2008 constitutional reform fortunately corrects this problem by establishing a constitutional interlocutory question. Said question is original in part as it presents two particularities compared to the one that can be observed in other countries: it can be raised only when it is argued that the law breaks rights and liberties protected by the Constitution; only the Administrative and Civil High Courts (Conseil d'Etat and Cour de Cassation) can raise it before the Constitutional Council. As it has been the case for a long time, the ordinary judge can control the compliance of laws with international treaties, the issue is to determine whether the new system of control of constitutionality of laws will be competing with this traditional "treaty" compliance of the laws.

RESUMEN: El hecho de que el control de constitucionalidad de las leyes en Francia sea principalmente un control abstracto a priori plantea un problema crucial: el control de constitucionlaidad de las leyes ya en vigor y que no fueron controladas en su dia por el Conseil Constitutionnel. La reforma constitucional del 23 de julio de $2008 \mathrm{co}-$ rrige afortunadamente este problema con la instauración de una cuestión prejudicial de constitucionalidad. Esta cuestión es parcialmente original porque presenta dos particularidades con respecto a lo que se puede encontrar en otros países: se puede plantear solamente cuando se alegue que la ley viola derechos y libertades garantizados por la Constitución; unicamente pueden plantear la cuestion ante el Conseil constitutionnel el Conseil d'Etat o la Cour de cassation. Desde hace muchos años, el juez ordinario puede controlar la conformidad de las leyes con los convenios internacionales, asi pues el problema es saber si el nuevo sistema de control de la constitucionalidad de las leyes le hara competencia a este tradicional sistema de control de la "convencionalidad" de las leyes. 
KeY WORDS: Constitutional Interlocutoray Question. Particularities. Compliance with international treaty control. Competition with the judicial review of laws.

PALABRAS Clave: Cuestión prejudicial de constitucionalidad. Especificidad. Control de la conformidad de las leyes con los convenios internacionales. Competencia con el control de la constitucionalidad de las leyes. 